\title{
O ESTADO DA ARTE DA CIRURGIA DO BAÇO, NO INÍCIO DO SÉCULO XXI
}

\section{THE STATE-OF-THE-ART IN THE SURGERY OF THE SPLEEN, IN THE BEGINNING OF THE $21^{\text {ST }}$ CENTURY}

\author{
Marcelo Campos Christo, TCBC-MG ${ }^{1}$
}

\begin{abstract}
"Remover o baço... tem sido para cirurgião... preceito imposto pela autoridade das gerações. Reconhece-se na atualidade, ser imerecido o atestado de inocência passado à esplenectomia e lamenta-se que, aceito sem maior exame, houvesse concorrido para o marasmo técnico da cirurgia do baço por muito tempo imobilizada no repertório de um ato só".
\end{abstract}

(Salomão Kaiser)

Do ponto de vista da sua importância na regulação do equilíbrio orgânico, em que circunstâncias seria o baço um órgão - essencialmente - bem sucedido? Essa pergunta que ficou sem resposta satisfatória ao longo de quase toda a evolução do conhecimento médico - só começou a ser convincentemente respondida a partir da segunda metade do século XX, quando o "perfil das asplenias" passou a ser analisado em função da abertura de uma nova e luxuriante fronteira microbiológica: a das interações entre hospedeiros asplênicos, comunidades microbiais e desequilíbrios microambientais.

A noção - introduzida na prática médica há 50 anos ${ }^{2}$ - de que preservar o baço seria sinônimo de salvaguardar mecanismos imunitários efetivos contra "microorganismos" - tornados eventualmente invasivos e causadores de doenças (cepas clonais) - acabou por provocar o surgimento de uma enorme quantidade de informações descritivas sobre a apreciação do valor imunitário e ecológico do órgão, numa escalada muitas vezes mais reveladora da importância pivotal da função esplênica no direcionamento da evolução de infecções microbiais, do que tudo aquilo que, até então, havia sido transmitido a sucessivas gerações de médicos ${ }^{3-4}$.

Em que proporção possa o baço ter influência na manutenção de um equilíbrio saudável entre o mutualismo e a virulência de comunidades de microorganismos: comensais e patógenos, que - como um vasto "continuum" - se hospedam normalmente no organismo é uma questão não resolvida. Mas é, sem dúvida, o baço um elo crucial na cadeia de eventos que propiciam uma resposta imunitária efetiva, seletiva e adequada contra cepas geneticamente modificadas, capazes de eventualmente agregarem valores patogenéticos - tais como a replicação fulminante - à dinâmica dos seus seqüenciamentos genéticos.

Ilustrando a "unicidade ancestral" imunitário de defesa orgânica, o baço funciona como um "nicho ecológico" - entre "imunidade inata" e "imunidade adaptativa" - atuando "centralmente" para limitar a expansão eminente de versões estocásticas de cepas microbiais emergentes, despertadas em suas características virulentas por modificações micro-ambientais. Interagindo - ecologicamente - com a imunidade inata (não específica), o baço rastreia essas cepas emergentes, circunscrevendo eficientemente a disseminação desses microorganismos. E, através das "citoquinas"7-8 o baço integrado à imunidade "adaptativa" modula a seletividade circunstancial de mecanismos de defesa imunitária adaptados à geração de anticorpos específicos e à preservação do equilíbrio eco-imunitário.

Por outro lado, o baço só veio a ter sua visibilidade imunológica, sua biologia funcional e sua importância clínica corretamente correlacionadas após meta-análises das evoluções clínicas de coortes de pacientes asplênicos - desenvolvidas com pesquisas de grandes séries cooperativas que desvendaram tendências de longo prazo e que vieram a identificar as asplenias como um "confluente modelo preditor" do desencadeamento de episódios infecciosos fulminantes (OPSI: Overwhelming Post Splenectomy Infection) ${ }^{3}$, não obstante a imprevisibilidade individual, espacial e temporal dessas ocorrências e a espectral diversidade das nosologias nelas envolvidas ${ }^{4}$. Essa percepção abriu os olhos da comunidade médica para uma nova fronteira da medicina preventiva: a da preservação do equilíbrio eco-imunitário do organismo, envolvendo microorganismos e seus hospedeiros ${ }^{9-12}$.

Essas evidências epidemiológicas de natureza categórica repetidamente documentadas ao longo dos últimos cinqüenta anos - caracterizando versões estocásticas de um modelo clínico determinístico - mantiveram abertos os caminhos para a aceitação, cada vez maior, de procedimentos cirúrgicos e condutas conservadoras, visando salvaguardar o elo estrutural do baço na cadeia das interações que mantêm a dimensão ecológica e a biodiversidade microbial orgânica, moduladas por um sistema imunitário espacialmente difuso 5 .

Os caminhos para a criação de modelos cirúrgicos "regrados" para conservar o baço começaram a ser desvendados ainda nos anos 50.

1.Hospital Felício Rocho - BH.

Recebido em: 31/05/2005

Aceito para publicação em: 26/09/2005

Trabalho realizado na Faculdade de Medicina da UFMG. 


\section{Paradigmas morfológicas}
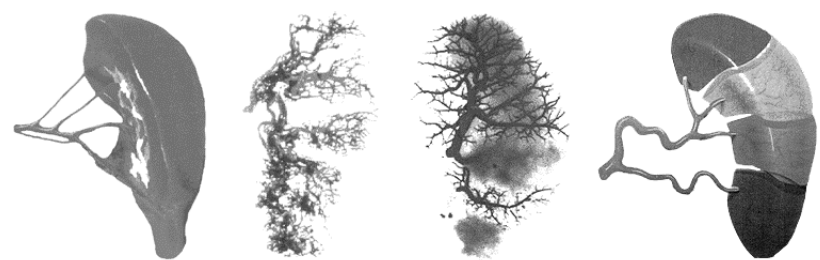

Figura 1 - Segmentação esplênica: distribuição de acordo com os vasos hilares.

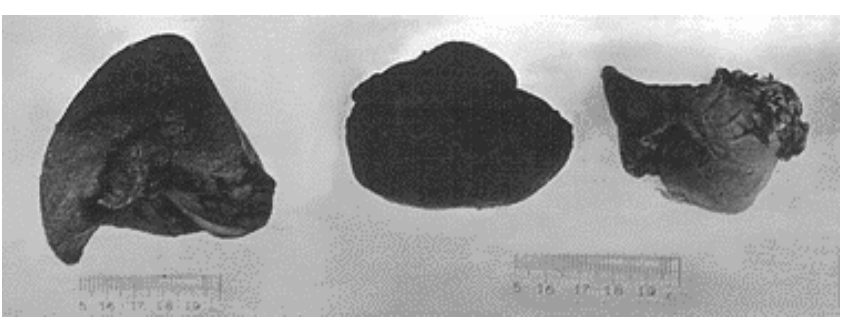

Figura 2 - Lesões traumáticas: espécimes de segmentos ressecados.

Em uma série de experimentos elegantes e bem conduzidos - Faculdade de Medicina da UFMG, em Belo Horizonte - Liberato Di Dio, então catedrático de Anatomia, e seus associados (Antônio Zapalá e Abadio Marcos Neder) desvendaram a estrutura angio-fractal do parênquima esplênico utilizando moldes de acetato de vinil e angiogramas dos vasos intraparenquimatosos. A esse grupo de pesquisadores juntou-se um cirurgião (Marcelo Campos Christo) que, com a cooperação dos pesquisadores anatomistas, e com o apoio e as facilidades que lhe foram concedidas pelo professor João Resende Alves, pode reproduzir - no laboratório da então Cátedra de Técnica Operatória e Cirurgia Experimental - os estudos anatômicos em baços humanos não fixados (Figura 1) e sistematizar experimentalmente, em cães, modelos cirúrgicos de esplenectomias parciais. E, em seguida, pela primeira vez, ressecções parciais do baço - baseadas no respeito à distribuição dos segmentos anatomocirúrgicos do parênquima foram executadas no Hospital de Traumatologia João XXIII (então Hospital do Pronto Socorro de Belo Horizonte) e, entre agosto de 1959 e julho de 1960, oito pacientes foram submetidos a diversas ressecções segmentares de parênquima esplênico atingidos por lesões traumáticas, em operações bem sucedidas (Figura 1, Tabela 1).

Com essa investigação foi possível estabelecer a sistematização operacional das esplenectomias parciais - baseadas em evidências anatômicas - que foram então chamadas de "sistematizadas / réglées (regradas)" 13-17 - termo empregado para expressar seu relacionamento harmônico com paradigmas morfológicos e modulações funcionais - que deram origem a uma tese acadêmica e foram posteriormente testadas com sucesso no controle de hiperesplenismos e de doenças hematológicas ${ }^{15}$ (Figura 2, Tabela 2).

Tecnicamente desenvolvidas com a utilização de procedimentos cirúrgicos convencionais, e reputadas como "um evento histórico na cirurgia do baço"18-19, as esplenectomias parciais regradas têm sido realçadas como um exemplo clássico de "pesquisa acadêmica" que precipitou a modernização da cirurgia esplênica. E, uma vez incorporadas ao repertório técnico dos cirurgiões, têm sido repetidamente revigoradas e universalizadas pela introdução de procedimentos minimamen-

Tabela 1 - Resultados das oito primeiras esplenectomias parciais em pacientes submetidos à exploração abdominal e/ou torácica por trauma (Hospital João XXIII, Belo Horizonte, período de 14/08/1959 a 24/07/1960).

\begin{tabular}{|c|c|c|c|c|c|c|}
\hline $\begin{array}{l}\text { Idade I } \\
\text { Sexo }\end{array}$ & Cirurgia do baço & $\begin{array}{l}\text { Esplenectomias } \\
\text { parciais }^{*}\end{array}$ & Lesões associadas & Via de acesso & Complicações & Resultados \\
\hline $40 / M$ & $\begin{array}{l}\text { Segmentectomia } \\
\text { polar inferior }\end{array}$ & & Diafragma & $\mathrm{TFL}^{\star \star}$ & Não & Curado \\
\hline $6 / F$ & $\begin{array}{l}\text { Segmentectomia } \\
\text { intermediária }\end{array}$ & & Diafragma e pulmão $\mathrm{E}$ & TFL & Não & Curado \\
\hline $23 / M$ & $\begin{array}{l}\text { Segmentectomia } \\
\text { polar superior }\end{array}$ & & Diafragma e pericárdio & TFL & Pericardite traumática & Curado \\
\hline $48 / M$ & $\begin{array}{l}\text { Segmentectomia } \\
\text { polar superior }\end{array}$ & & Estômago & Laparotomia & Infecção & Óbito \\
\hline $17 / M$ & $\begin{array}{l}\text { Hemiesplenectomia } \\
\text { superior }\end{array}$ & & Diafragma e epíplon & TFL & Não & Curado \\
\hline $27 / M$ & $\begin{array}{l}\text { Hemiesplenectomia } \\
\text { superior }\end{array}$ & & Não & Laparotomia & Não & Curado \\
\hline $16 / M$ & $\begin{array}{l}\text { Hemiesplenectomia } \\
\text { superior }\end{array}$ & & $\operatorname{Rim} E$ & TFL & $\begin{array}{l}\text { Infecção na ferida } \\
\text { operatória }\end{array}$ & Curado \\
\hline $22 / M$ & $\begin{array}{l}\text { Segmentectomia } \\
\text { polar superior }\end{array}$ & & $\begin{array}{l}\text { Diafragma, pulmão E, coluna } \\
\text { vertebral e medula espinhal }\end{array}$ & TFL & Paraplegia traumática & Curado \\
\hline
\end{tabular}

*Para fins didáticos, o baço foi sempre representado como composto por quatro segmentos.

**As tóraco-freno-laparotomias eram empregadas, então, como rotina na exploração dos ferimentos envolvendo abdome e tórax. 
Tabela 2 - Esplenectomias parciais hematológicas (Hospital Felício Rocho*, início: janeiro de 1975).

\begin{tabular}{|c|c|c|c|c|c|}
\hline Diagnóstico & $\begin{array}{l}\mathrm{N}^{0} \mathrm{de} \\
\text { casos }\end{array}$ & $\begin{array}{l}\text { Idade } \\
\text { (anos) }\end{array}$ & $\begin{array}{c}\text { Óbitos } \\
\text { hospitalares }\end{array}$ & $\begin{array}{c}\text { Seguimento } \\
\text { pós-operatório }\end{array}$ & Resultado clínico \\
\hline $\begin{array}{l}\text { Doença de } \\
\text { Gaucher (Tipo I) }\end{array}$ & 6 & 5 a 29 & 1 & Até 15 anos & Qualidade de vida $\uparrow$ \\
\hline Mielofibrose & 3 & 6 a 57 & 0 & Até 17 anos & Qualidade de vida $\uparrow$ \\
\hline $\begin{array}{l}\text { Púrpura } \\
\text { Trombocitopênica } \\
\text { Idiopática }\end{array}$ & 5 & 5 a 11 & 0 & Até 1 ano & $\begin{array}{l}\text { Resposta transitória } \\
\text { inicial } \uparrow \text {, seguida de } \\
\text { recidiva (todos) }\end{array}$ \\
\hline $\begin{array}{l}\text { Síndrome Mielo- } \\
\text { proliferativa } \\
\text { Aguda }\end{array}$ & 1 & 2 & 0 & 3 meses & Alívio da dor \\
\hline
\end{tabular}

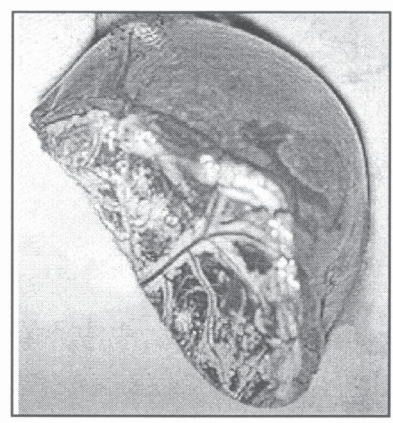

Doença de Gaucher: ressecção sub-total - segmento polar cranial conservado. Superficie de secção recoberta pelo grande epíplon.

* Com a colaboração do Professor Romeu Ibrahim de Carvalho.

te invasivos propiciados pelos extraordinários avanços tecnológicos colocados a serviço da habilidade médica ${ }^{20}$. Iniciava-se um novo ciclo na cirurgia esplênica - perspectivas de abordagens "invasivas" do parênquima haviam sido claramente demonstradas, representando uma mudança dramática de pontos de vista profissionais em relação ao baço. E nos anos que se seguiram aos nossos relatos pioneiros pudemos verificar que as esplenectomias parciais - baseadas nos paradigmas do mapeamento estrutural do baço - haviam sido capazes de otimizar as expectativas dos cirurgiões sobre a abordagem do órgão e de alargar, definitivamente, as metas da cirurgia esplênica ${ }^{19-26}$. E, na narrativa médica - no exercício da arte e na comunicação cientifica - as expressões: esplenectomias parciais regradas, esplenectomias parciais transsegmentares, esplenectomias sub-totais, hemiesplenectomias, segmentectomias esplênicas, manejo conservador de hiperesplenismo, embolizações parciais seletivas da artéria esplênica, esplenectomias parciais laparoscópicas - aplicadas ao tratamento de lesões traumáticas, de doenças hematológicas e de outras condições patológicas envolvendo o baço - passaram a freqüentar correntemente a linguagem profissional. Um novo padrão de raciocínio clínico e uma nova estratégia de comportamento cirúrgico passaram a integrar os usos e costumes do profissionalismo médico em relação ao baço. E as esplenectomias parciais, reguladas por paradigmas estruturais, seguem em frente conquistando governança clínica e credibilidade ética capazes de inspirar a experimentação de proposições técnicas pensadas para salvaguardar a integridade angio-estrutural, a interação eco-imunitária e a eficiência operacional do baço para intermediação de respostas imunitárias seletivas, representando - para a Medicina como um todo - "o fim de uma longa inibição doutrinária"1.

\section{AGRADECIMENTOS}

Ao Conselho Diretor da Fundação Felice Rosso pelo apoio técnico e, especialmente, a Sra. Patrícia Lapertosa pelo trabalho de editoração eletrônica.

\begin{abstract}
In the last fifty years evolution of scientific knowledge on the spleen provoked an entirely new approach to splenic surgery. It was shown that virulence may emerge as a significant consequence of environmental and evolutionary changes of some microbial communities, and devastating pathogenetic results of these changes become visible in human hosts without the splenic function. In other words: the spleen plays a pivotal role in the dynamic balance between biodiversity, microorganisms and immunogenecity in human hosts. Therefore, to preserve the "splenic immunologic repertoire" became an increasing commitment among surgeons. Understanding the integration of these multiple information on spleen, seems central to understand the new splenic surgery. Partial splenectomies (Réglées) - based on anatomical, experimental and clinical studies, developed at the University of Minas Gerais since the fifties - were successfully applied initially to treat the traumatic injuries of the spleen; in a following step, partial splenectomy were used to control hematological diseases. "Réglées" techniques on the spleen have conquered "ethical support, consilience status and clinical governance" to give birth to surgical therapeutic decisions on the spleen, in order to spare the structural integrity of the immune system. Splenic réglées procedures became a seminal achievement of splenic surgical practice. Initial results of "Partial splenectomies" - with conventional surgical armamentaria and techniques - were confirmed and improved by the introduction of techniques based on laparoscopic and endovascular approaches. And current usage of surgical splenic saving procedures propitiated the emergence of an appropriate lexicon for medical communication and became an "end point" of a "long-standing surgical inhibition" over the spleen (Rev. Col. Bras. Cir. 2005; 32(5): 279-282).
\end{abstract}

Key Words: Spleen; Spleen/immunology; Spleen/wounds and injuries; Splenectomy; Laparoscopy; Sepsis; Surgery. 


\section{REFERÊNCIAS}

1. Kaiser S. Tratamento cirúrgico sem esplenectomia do trauma do baço [editorial]. Rev Col Bras Cir. 1981;8(6).

2. King H, Schumacker H. Splenic studies: susceptibility to infection after splenectomy performed in infancy. Ann Surg. 1952;136: 239-42.

3. Donadi AE, Falcão RP. Imunidade em infecções em esplenectomizados. Rev Paul Med. 1999;107:175-80.

4. Singer, DB. Postsplenectomy sepsis. Perspect Pediatr Pathol.1973,1:285-311.

5. Fearon DT, Locksley RM. The instructive role of innate immunity in the acquired immune response. Science. 1996; 272(5258):50-3.

6. Peterson AT, Sober J, Sánchez-Cordero V. Conservatism of ecological niches in evolutionary time. Science. 1999; 285(5431):1265-7.

7. Cyster JG. Chemokines and cell migration in secondary lymphoid organs. Science. 1999; 286(5447):2098-102.

8. Randolph DA, Huang G, Carruthers CJL, et al. The role of CCR7 in TH1 and TH2 cell localization and delivery of B cell help in vivo. Science. 1999;286(5447):2159-162.

9. Ochsenbein AF, Fehr T, Lutz C, et al. Control of early viral and bacterial distribution and diseases by natural antibodies. Science. 1999; 286(5447):2158-9.

10. Read AF, Taylor LH. The ecology of genetically diverse infections. Science. 2001;292(5519):1099-102.

11. Levin BR, Lipsitch M, Bonhoeffer S. Population biology, Evolution, and infectious disease: convergence and synthesis. Science.1999;283(5403):806-9.

12. Hoffmann JA, Kafatos FC, Janeway CA, et al. Phylogenetic perspectives in innate immunity. Science.1999;284(5418): 1313-5.

13. Campos Christo M. Segmental resections of the spleen. Report on the first eight operated on patients. Hospital.1962;62:187204.

14. Campos Christo M. Esplenectomias parciais sistematizadas réglées [dissertação]. Belo Horizonte(MG): Universidade Federal de Minas Gerais; 1961.
15. Campos Christo M. Anatomical and experimental basis of partial splenectomies. Rev Bras Cir. 1963;46(1):80-90.

16. Campos Christo M. Partial splenectomies in hematologic diseases. Chirurgic Gastroenterol. 1993;9(suppl 2):23-9.

17. Campos Christo M, Di Dio LJA. Anatomical and surgical aspects of the splenic segmentectomies. Ann Anat. 1987; 179:461-74.

18. Mc Clusky DA, Skandalakis LJ, Colborn GL, et al. Tribute to a triad: history of splenic anatomy, physiology and surgery - part 2. World J Surg. 1999: 23(5):514-26.

19. Morgenstern L. A history of splenectomy. In: Hiatt JR, Phillips EH, Morgenstern L, editors. Surgical diseases of the spleen. $1^{\text {st }}$ ed. New York: Spring-Verlag; 1997. p. 3-14.

20. Poulin EC, Thibault C, Des Coteaux JG et al. Partial laparoscopic splenectomy for trauma: technique and case report. Surg Laparosc Endosc. 1995; 5(4):306-10.

21. Abrantes WL, Lucena MS, Schloback MC. Cirurgia conservadora do trauma esplênico na criança. Rev Ass Med Bras. 1994;40(2):113-7.

22. Pringle KC, Spigos DG, Tan WS, et al. Partial splenic embolization in the management of thalassemia major. J Pediatr Surg. 1982;17(6):884-91.

23. Dwivedi MK, Pal RK, Dewanga L, et al. Efficacy of partial embolization in the management of hypersplenism. Ind J Radiol Imag. 2002; 12(3):371-4

24. Hoeckstra HJ, Tamminga RY, Timens W. Partial splenectomy in children: an alternative for splenectomy in the pathological stading of Hodgkin's disease. Ann Surg Oncol. 1994;1(6):480-6.

25. Diaz AS, Iturriagoitia BS. La esplenectomia parcial sobrepasa los pronósticos. Rev Cubana Cir. 2003;42(1):42-8.

26. Sarker A, An C, Davis M, et al. Inflammatory pseudotumor of the spleen in a 6-year-old child: a clinicopathologic study. Arch Pathol and Laborat Med. 2003;127(3):127-30.

Endereço para correspondência:

Marcelo Campos Christo

Rua Dias Toledo, 76 - Vila Paris

30380-670 Belo Horizonte - MG

camposchristo@yahoo.com.br 